\title{
THE ACHILLES HEEL OF WILD LIFE PRESERVATION
}

\author{
By R. Y. Edwards
}

This paper deals with two ideas that are not new but which are too often forgotten. The writer can speak only from North American experience, but these ideas have worldwide importance. They are that wild life preservation is complete only when the species concerned are maintained in their natural surroundings ; and that preservation efforts often fail because of blind faith in reserves while the importance of environment is ignored.

Animals are intricately adjusted to specific habitats. Only when the animal and its habitat are preserved together is the animal truly saved. The concentration of preservation efforts upon the animal itself while ignoring the land it inhabits with its fauna and flora can have only the uncertain success of trying to grow any living thing with little regard to its needs. In wild life these needs can be many things - water, a certain topography, kinds of vegetation or the abundance of a certain plant, soil chemistry, orientation of land relative to the sun or lack of competition from other animal species. Every animal has a host of these needs recognizable only through research or by acute observation in some cases. People with this approach to studying animals can often identify tracts of land as ideal for an animal species with remarkable speed and accuracy. Since each species is a product of parts of this world having distinct attributes, these may be almost as definite and definable as is the species itself.

The modern trend in wild life protection and management is to deal with the animal through its environment. Hunting, poaching, trapping and predation, although important in some cases, were once taken far too seriously in America. These were often blamed for wild life decreases that had far more basic, but less obvious, causes. Some examples from the mountains of Western Canada will illustrate this point. Agriculture has eliminated far more deer herds than have hunters, through destroying key areas essential for winter survival. Extensive brushlands resulting from forest fires have resulted in some places in a remarkable increase in moose (Alces americana), despite abundant hunters taking thousands as an annual harvest. Logging and fires, not overtrapping, are eliminating our marten (Martes americana) over large areas. Competition for food 
with domestic sheep and cattle is exterminating some herds of bighorn sheep (Ovis canadensis) that are not hunted. Small patches of warm lands facing the south, and hence the winter sun, are the key to deer survival in districts with heavy snowfall, and the carrying capacity of these small areas alone is frequently the major control on deer abundance. Years of unusually deep snow drastically reduce many species such as deer, moose, elk (Cervis canadensis) and perhaps even some forms of caribou (Rangifer arcticus). Deep snows are also a major control on our larger predators, such as wolves (Canis lupus), coyotes (Canis latrans) and cougars (Felis concolor). This may be either indirectly because snow affects their prey or directly through hampering travel. The abundance of these species may be determined by snow, and not by man, despite heavy hunting.

These examples are brief and perhaps over-simplified, but they illustrate the new trend in wild life biology. These are among the most important factors controlling the abundance of much of our wild life, and sometimes only one such factor causes the difference between abundance and scarcity. These are often obscure factors despite their importance. These are the Achilles heel of wild life preservation because their importance is not widely recognized. Let us have high ideals and man-made laws to be sure, but these are not enough. The laws of nature should not be ignored. Our greatest need is study, that we may know these laws and how they control the numbers of disappearing wild life. With knowledge the way to wild life abundance is frequently quite obvious, while in other cases hopeless efforts are recognizable as such and alternative measures may be proposed before valuable time is lost.

Time is running out for much of the world's most spectacular wild life. Perhaps the ecological approach to preservation will succeed where others have failed. 